\title{
MOTIVAÇÃO DOS DISCENTES A PARA ESCOLHA DO CURSO DE CIÊNCIAS CONTÁBEIS EM UMA INSTITUIÇÃO DE ENSINO SUPERIOR PRIVADA
}

\author{
Lilian Patrícia Dias de Souza \\ Edinaldo Victor de França Pereira \\ Nathalia Suelen Pereira Pita Freitas de Moura \\ Faculdade Santa Helena - FHS (Brasil) \\ João Gabriel Nascimento de Araújo \\ Tiago de Moura Soeiro \\ Universidade Federal de Pernambuco - FHS (Brasil)
}

\begin{abstract}
Resumo. A motivação dos discentes é considerada uma energia dinamizadora dos processos de ensino e de aprendizagem capaz de atingir todas as etapas da educação. Diante de sua relevância, esta pesquisa teve como objetivo detectar os motivos que influenciaram discentes de uma instituição privada na escolha do Curso de Ciências Contábeis. No desenvolvimento do estudo, foi aplicada uma escala elaborada no campo da psicologia vocacional, composta por 31 indicadores baseados em três modelos: econômico, psicológico e social. Participaram do estudo 124 respondentes dos primeiros e segundos períodos do Curso de Ciências Contábeis de uma Instituição de Ensino Superior da rede privada, localizada na região metropolitana do Recife. Os resultados indicam que, entre as razões de interferência na escolha profissional pela dimensão econômica, destaca-se o fato de esta ser uma carreira que oferece maiores ofertas de emprego e permite atuar em diferentes áreas/segmentos da empresa, além de ser uma profissão que se mantém atualizada com as evoluções do mercado. Em relação à dimensão social, destacou-se o prestígio do curso. Sobre a dimensão psicológica, evidenciou-se a concepção dos estudantes de que, ao escolher o curso, têm a possibilidade de ampliar sua cultura geral e seu desenvolvimento intelectual.
\end{abstract}

Palavras-chave: Motivação, Ciências Contábeis, Teoria Vocacional.

\section{MOTIVATION OF STUDENTS WHO CHOSE TO MAJOR IN ACCOUNTING AT A PRIVATE HIGHER EDUCATION INSTITUTION}

\begin{abstract}
Student's motivation is considered to be a source of dynamic energy to the teaching and learning processes in all levels of education. This piece of research aims at identifying the reasons that led students of a private institution to chose the Accounting major. In the study we made use of a scale from vocational psychology (career counseling) composed of 31 indicators based on three distinct models: the economical, the psychological and the social models. 124 participants from the first and second semesters of Accounting at a private university in Recife took part in the study. Results indicate that among the economical reasons for choosing the Accounting major there is the high absorption by the job market, the possibility of working in different segments of a company, and the fact that the profession is constantly updated as the market evolves. Regarding the social dimension, participants highlighted the renown of the major and, in the psychological dimension, the possibility of expanding their cultural knowledge and fostering their intellectual development were the main reasons mentioned.
\end{abstract}

Keywords: Motivation, Accounting, Vocational Theory. 


\title{
MOTIVACIÓN DE LOS DISCENTES PARA ELEGIR CIENCIAS CONTABLES EN UNA INSTITUCIÓN DE ENSEÑANZA SUPERIOR PRIVADA
}

\begin{abstract}
Resumen. La motivación de los discentes se considera una energía dinamizadora del proceso de enseñanza-aprendizaje, que es capaz de llegar a todos los niveles de la educación. El objetivo de esta investigación es detectar los motivos que llevaron a discentes de una institución privada a elegir la Carrera de Ciencias Contables. Durante el desarrollo del estudio, se aplicó una escala elaborada en el campo de la psicología vocacional, y que se componía por 31 indicadores basados en tres modelos: económico, psicológico y social. En el estudio participaron 124 respondientes del primer y segundo semestre de la carrera de Ciencias Contables de una Institución de Enseñanza Superior de la red privada, ubicada en la región metropolitana de Recife, la capital del estado de Pernambuco, en el nordeste de Brasil. Los resultados señalan que, entre las razones de interferencia en la elección profesional en relación con la dimensión económica, se destaca el hecho de que es una carrera que ofrece más ofertas de empleo y que permite actuar en diferentes áreas/segmentos de una empresa, además de que es una profesión que se mantiene actualizada con la evolución del mercado. Con relación a la dimensión social, se destacó el prestigio de la carrera y, en cuanto a la dimensión psicológica, la concepción de los estudiantes de que al elegir la carrera tendrían la posibilidad de ampliar su cultura general y su desarrollo intelectual.
\end{abstract}

Palabras clave: Motivación, Ciencias Contables, Teoría Vocacional.

\section{Introdução}

As constantes mudanças socioeconômicas do mundo moderno e a velocidade dos avanços tecnológicos exigem reformulações nas atitudes daqueles que atuam ou pretendem atuar no mercado de trabalho. Uma das alternativas para os que pretendem iniciar uma carreira se constitui pelo ingresso em cursos de graduação, condição que possibilita ampliar perspectivas para os âmbitos pessoal e profissional.

A opção pelo Ensino Superior tem relação com a escolha profissional, ocorrida geralmente na adolescência, um período em que o "jovem não está preparado para uma tomada de decisão deste nível” (Miranda, 2001, p. 78). Por isso, o autor ressalta a importância do acesso a informações sobre a profissão pretendida.

Essas informações, contudo, precisam ser objetivas, já que o grande volume disponível atualmente, além das incertezas quanto ao mercado de trabalho, podem influenciar em escolhas equivocadas, ampliando a pressão sobre os jovens. Em contrapartida, uma escolha bem definida favorece aos futuros profissionais o "preparo para enfrentar as dificuldades relacionadas com sua profissão, sempre com o intuito de buscar soluções... baseadas na prática do dia-a-dia e por meio do conhecimento adquirido na universidade" (Kroenke, Cardoso e Dominguez, 2009, p. 4).

Além do ingresso no Ensino Superior, a permanência é outro fator a ser considerado quando nos referimos à profissionalização. Por isso, Guimarães, Bzuneck e Sanches (2002) mencionam a existência de muitos estudos com ênfase na motivação nos contextos educacionais, sendo que parte tem se dedicado a encontrar formas de influenciar os estudantes para incrementarem seu envolvimento em atividades de aprendizagem.

Almeida, Zwierewicz e Pantoja (2018), por exemplo, realizaram um estudo sobre motivação, envolvendo discentes de uma universidade da Espanha. Seu objetivo foi delimitar o perfil sociodemográfico, emocional e motivacional de matriculados na 
modalidade blended learning e que utilizam a Plataforma Moodle, destacando na análise dos dados a relação entre o manejo emocional e a motivação para os estudos.

A motivação dos discentes é considerada uma energia dinamizadora dos processos de ensino e de aprendizagem. Ela atinge todas as etapas da educação e influencia tanto no tempo dedicado aos estudos como no desempenho escolar, além de afetar o nível de satisfação que se dimensiona na relação bem-estar versus mal-estar (Lens, Matos e Vansteenkiste, 2008). Para esses autores, a motivação se constitui por um processo psicológico e no qual interatuam 'características da personalidade', entre as quais, as razões, habilidades, interesses, expectativas e perspectiva de futuro, e as 'características ambientais percebidas', podendo ser modificada por meio de mudanças nos próprios estudantes, no seu ambiente de aprendizagem ou na cultura escolar.

Nesse sentido, a psicologia vocacional nos fornece contribuições que ajudam a compreender as motivações da escolha da profissão. Dentre o arcabouço conceitual da área, elegemos três modelos para direcionar este estudo: o modelo das teorias psicodinâmicas (de natureza psicanalítica, analisa aspectos internos, como fatores emocionais, na seleção da profissão), o modelo econômico (verifica a influência dos elementos socioeconômicos na escolha profissional) e o modelo sociológico (analisa a influência do contexto cultural e social para a seleção da profissão).

Diante do exposto, esta pesquisa teve como objetivo detectar os motivos que influenciaram discentes de uma instituição privada na escolha do Curso de Ciências Contábeis. Por se tratar de uma questão ainda pouco explorada nas publicações vinculadas à área, este estudo é justificado pela possibilidade de compreender o que leva um jovem a optar pelo referido curso, sendo que os resultados podem contribuir para redimensionar ações voltadas ao atendimento das especificidades que os estudantes apresentam.

Reitera-se que a falta de compreensão sobre as implicações de optar por uma área ao ingressar no Ensino Superior pode acarretar em problemas difíceis de transpor. Diante dessa condição, Bomtempo (2005, p. 34) afirma que "a exploração das teorias vocacionais prender-se-á em colaborar na explicação de fatores de influência na escolha."

Entre as propensões conceituais desenvolvidas no campo da psicologia vocacional, parte delas será contextualizada na sequência, no sentido de evidenciar as razões de interferência na escolha profissional.

O modelo desenvolvimentista da escolha profissional é um dos referenciais teóricos a ser considerado. Esse modelo tem como um dos maiores representantes o pesquisador Donald Super, apesar de ter sido Balbinotti (2003) ${ }^{\mathrm{i}}$ que recomendou, no livro The Dinamics of Vocational Adjustment, a criação de distinções profissionais baseadas em concepções (maturidade, interesse, valores etc.), englobando outros quatro paradigmas que mostrariam mais claramente as dificuldades na conduta vocacional: o modelo de perspectiva diferencial, o modelo socioeconômico e ambiental, o modelo desenvolvimentista e o modelo fenomenológico.

A teoria vocacional desenvolvida por Super e outros colaboradores foi aprimorada por mais de sessenta anos de pesquisas. Com auxílio de Ginzberg, Super se transformou em um dos precursores da compreensão da conduta vocacional segundo um ponto de vista evolutivo. Nesse processo, Super (1957) destacou que a ocupação deixou de ser percebida como a opção por uma profissão em função da clara semelhança entre os aspectos pessoais e profissionais. Em um preciso instante da história, ela passou a ser 
compreendida como um sistema que se sucede no tempo de todo o ciclo e espaço de vida (life-span, life-pace theory).

Super levava em conta um modelo claro em sua teoria e o situava em constante desenvolvimento. Ele apresentou, em 1951, a perspectiva do padrão de carreira, com o propósito de realizar uma tese sobre a decisão profissional fundamentada na Psicologia de Desenvolvimento. No olhar de Bomtempo (2005, p. 37), "tem-se aqui o princípio da exploração da carreira ocorrendo ao longo da vida, e não o de uma escolha profissional num dado momento." Tal tese compreende o avanço vocacional como um meio regular, que contempla o período da infância até a maturidade.

À sua primária concepção foram somadas pressuposições desenvolvimentistas em relação ao entendimento da profissão, as quais descreviam condutas vocacionais com que os indivíduos defrontar-se-iam à proporção que progredissem em suas carreiras ao longo da vida. Mais tarde, essa concepção complementou-se com o ponto de vista fenomenológico, que ressaltou em maneiras de a profissão ver a si mesma e esclareceu dúvidas sobre os processos de criação e tradução, bem como sobre a prática das preferências. Ainda de acordo com Super, percebeu-se nesse percurso que o orgulho de si mesmo e a convicção de capacidade passaram a ser vistos como elementos de autoavaliação.

À última concepção foi somado o ponto de vista interpretativo, que compreende as funções sociais e a relevância de estender o olhar do desenvolvimento da carreira para além do papel do funcionário, englobando toda a série de papéis sociais praticados e enriquecidos (Savickas, 1997). Esse modelo apresenta recursos aplicáveis tanto para adolescentes quanto para adultos, que podem ser explorados em diversas atividades e raciocínios.

Quando se trata da observação de jovens no sistema educativo, o foco concentrase nos regimes de tomada de decisão porque acentuam a fundamentação sem subestimar a maturidade vocacional. Quanto aos adultos, o modelo presta-se às oportunidades de informação e aos entendimentos pelos quais o indivíduo passa durante sua vida, bem como seus valores e atribuições, o que pode inspirar o aperfeiçoamento das suas carreiras (Super, 1957).

Muitos autores empenharam-se em tratar de diversos pontos de vista do avanço da escolha profissional baseados em modelos das teorias psicodinâmicas. Segundo Bimrose (2004), se relacionados a outras teorias do pensamento psicológico sobre a escolha da profissão, resultam em poucas melhorias no andamento das abordagens psicodinâmicas, no entanto, ideologias e concepções com base nesse ponto de vista teórico têm motivado uma reflexão produtiva sobre tal campo.

Conforme anunciado por Watkins e Savickas (1990), a prática da teoria psicodinâmica, no âmbito da instrução de carreira, relaciona-se a métodos que utilizam as motivações, as conveniências, os estímulos, as finalidades e outras mutantes de caráter inconsciente ou não claro na experiência de entender e investigar suas definições. De maneira total, então, a visão psicodinâmica da definição profissional tenta entender o modo como incentivos individuais, estímulos e finalidades interferem e contribuem no progresso vocacional (Bimrose, 2004).

Nas teorias psicodinâmicas, de acordo com Bock (2001), procura-se a explanação do modo como os seres humanos formam seu caráter e aproximam-se de suas carreiras. Essas teorias abordam conceitos que se baseiam na psicanálise, levando em conta o avanço afetivo sexual, especialmente no início da infância, para 
compreender as vocações, os benefícios e aspectos de individualidade. Pimenta (1979 apud Bock, 2001) e Silva (1996 apud Bock, 2001), registram que os representantes dessas teorias procuravam associar, de forma mecanicista, os conceitos de Freud e seus seguidores com as ocupações - ao determinarem modelos de caráter em função das convivências preservadas desde a infância.

As teorias psicodinâmicas percebem a conduta como objeto de esforço psicológico que se articula internamente, mas assiduamente fora de sua condição consciente. Os processos da mente, como emoção, motivação e pensamento, atuam simultaneamente e podem, desse modo, gerar sentimentos contrários e conflitantes.

Todos somos criaturas singulares, com ideal próprio de entendimento do mundo, credos e princípios. Esse acúmulo de elementos conduz nossas realizações e atrações não só na nossa vida pessoal, mas também na profissional. Nessa definição, Âncoras de Carreira se constituem pela personalidade pronta e refletida pelas práticas concentradas desde a infância até a maturidade.

Conforme Schein (1994), as Âncoras de Carreira interpretam o "Eu Verdadeiro" do profissional, visto que são elas que, de fato, revelam seus propósitos reais no que diz respeito ao trabalho. Isso esclareceria as justificativas de cada pessoa ao percorrer sua respectiva natureza, produzida com base em suas disposições e convicções.

Outro modelo, contudo, chamado de modelo econômico, lida como a atuação dos elementos socioeconômicos, tecnológicos e ambientais. Ele busca destacar, sobretudo, elementos como a economia, o mercado de trabalho e as expectativas profissionais a respeito da evolução da atividade. Esse modelo também interpela elementos sociológicos, como a família, a escola, a comunidade, o grupo de harmonia social, sendo oferecida atenção especial à sociedade, que acaba incumbindo certa profissão aos indivíduos, bem como os elementos que discriminam as pessoas em meio às profissões.

Com grande aprofundamento na década de 1990, esse método tem como premissa básica que as pessoas escolhem suas profissões visando aumentar seus ganhos e diminuir as perdas daquilo que valorizam. Cada profissão possui, portanto, um valor individual e particular para cada pessoa.

Dentro desse processo de orientação, a análise de atitudes, valores, esquemas cognitivos, expectativas, autoeficácia e objetivos pessoais buscam auxiliar nos processos de solução de problemas, tomada de decisão e estabelecimento de prioridades em relação à formação acadêmica ou ao encaminhamento profissional. Super (1957) defende que nesse percurso a família é fundamental para o aprendizado e na formação dos valores das crianças e dos adolescentes, fornecendo, nesse sentido, informações, desenvolvimento e habilidades que auxiliarão na escolha da carreira.

Algumas teorias lidam com conteúdos, tais como maturidade, interesses e valores, defendendo sua relevância por toda a extensão da evolução do ser humano. Elas explicam detalhadamente como é complexa a predisposição vocacional de cada pessoa. Os temas por elas explorados descrevem que, além da inspiração de fatores superficiais existentes na sociedade e no lugar em que o indivíduo vive, existem princípios internos, em consequência do que almeja e da respectiva identidade. Esses princípios se diversificam para cada jovem.

A análise via modelo sociológico, por sua vez, concentra-se na importância que a cultura e a sociedade têm no sistema de seleção, considerando elementos como classe 
social, momentos de educação, família, crença, raça e nacionalidade. A teoria do acidente, por exemplo, demonstra que a preferência e a evolução profissional são causadas, na maior parte, acidentalmente, ou seja, fora do comando do indivíduo (Super e Bohn Jr., 1980, p. 171). Assim, elementos como classe social e família, que são vistos como eficientes fatores de preferência profissional, são exemplos daquilo que não é decidido pelo indivíduo, mas por acidente.

Nesse sentido, as concepções dos jovens acerca de atividades almejadas são a reprodução de suas práticas nos grupos familiares e culturais. Caplow (1954) afirma que os filhos 'herdam' os cargos dos pais, adotando um ofício com vínculo em cargos que se conciliem com a classe social de que fazem parte.

É nesse contexto que os jovens compreendem a influência dos cargos dos pais e consideram que é confortável fazer parte do grupo de influência. Dessa forma, o jovem vai progredir na sua escolha a partir da cultura vigente e do histórico pessoal que interfere em seus propósitos vocacionais. Por isso, os estudos de Bomtempo e outros (2007) propagam que os ingredientes sociais definem a profissão e que há uma categoria no status social básico que abrangeria também os precedentes econômicos e psicológicos.

\section{Metodologia da pesquisa}

A abordagem metodológica mais apropriada para conduzir a pesquisa de identificação da motivação dos discentes para a escolha do curso de Ciências Contábeis de uma Instituição de Ensino Superior (IES) foi a de natureza descritiva do tipo Survey, que permitiu, por meio de um questionário, identificar os fatores de influência na escolha do curso superior. Para atingir os objetivos propostos, utilizamos como referência o instrumento do estudo realizado por Pinheiro e Santos (2010).

A coleta de dados envolveu uma amostra com 124 entrevistados. A instituição escolhida para a realização da pesquisa foi uma IES privada da região metropolitana do Recife, e os estudantes cursavam o final do $1^{\circ}$ e $2^{\circ}$ períodos, no turno da noite.

Esses discentes já estavam familiarizados com o ambiente universitário e, portanto, possuíam melhores condições para responder a um questionário sobre os possíveis fatores de motivação para a escolha do curso, atendendo recomendações de Durso, Cunha, Neves e Teixeira (2016). Além disso, escolheram-se estudantes dos períodos iniciais para ampliar o grau de confiabilidade da pesquisa, tendo em vista que os dos períodos seguintes já haviam sofrido interferências da academia, o que, supostamente, provocaria mudanças de comportamento, tanto positivas quanto negativas, que poderiam influenciar nos resultados obtidos.

O questionário foi dividido em duas partes. A primeira foi dedicada para apresentação da posição dos discentes associados ao curso, o contexto que abrangeu sua preferência e seus desejos para o futuro. Nessa etapa, as afirmativas eram dicotômicas.

A segunda parte consistiu na identificação dos prováveis elementos que direcionaram a escolha do curso, segundo uma abordagem baseada em três modelos: econômico, psicológico e social, derivados das contribuições de Bomtempo (2005). Para a segunda parte foi adotada uma escala de cinco pontos com o propósito de identificar o grau de concordância com as afirmações. 
Para a análise de dados, os resultados foram tabulados em uma planilha do Excel para facilitar sua leitura e inferência. Para efeitos de análise, todos os valores de porcentagens encontrados foram arredondados para até duas casas decimais após a vírgula.

Em relação aos procedimentos éticos, a pesquisa teve como valores fundamentais: honestidade intelectual, objetividade, imparcialidade, veracidade, justiça e responsabilidade. Assim, ela foi regida pelos princípios gerais relativos (i) ao consentimento informado, (ii) à preocupação em não prejudicar os participantes e (iii) em manter a confidencialidade das pessoas sempre que demandado (Saunders, Thornhill e Lewis, 2012). Destaca-se que esses valores fundamentais foram aplicados durante todo o processo de pesquisa, ou seja, na concepção, no desenvolvimento, na realização e na comunicação dos resultados.

\section{Resultados e discussão}

Considerando que o objetivo desta pesquisa foi detectar os motivos que influenciaram discentes de uma instituição privada na escolha do Curso de Ciências Contábeis, os resultados expressam a posição deles em relação ao curso, ao contexto que abrangeu sua preferência e aos desejos para o futuro, bem como os elementos que direcionaram a escolha do curso, vinculando-os aos modelos econômico, psicológico e social.

\section{Características da escolha e visão do curso}

Os feedbacks relativos à posição dos discentes associados ao curso e ao contexto que abrangeu sua preferência e seus desejos para o futuro foram condensados na Tabela 1. Os resultados indicam que a maior parte dos discentes estava cursando um Ensino Superior pela primeira vez $(63,7 \%)$, e a maioria estava segura de suas decisões no momento da escolha do curso $(76,6 \%)$.

Tabela 1

Situação e visão com relação ao curso

\begin{tabular}{|c|c|c|}
\hline \multirow[t]{2}{*}{ Questões } & \multicolumn{2}{|c|}{ Respostas \% } \\
\hline & Sim & Não \\
\hline 1. Este é o primeiro curso superior que está fazendo? & 63,7 & 36,3 \\
\hline 2. Antes deste curso, você participou de processos seletivos para outros cursos? & 50,8 & 49,2 \\
\hline 3. Você tinha informações suficientes sobre o curso quando fez sua escolha? & 64,5 & 23,4 \\
\hline 4. Sua decisão, no momento da escolha, foi segura? & 76,6 & 23,4 \\
\hline 5. Se você tivesse recursos (financeiros, tempo), você teria escolhido outro curso? & 71,8 & 28,2 \\
\hline 6. Quando você ingressou no curso, você estava empregado ou já havia trabalhado? & 75 & 25 \\
\hline 7. Se fosse hoje, você optaria novamente pelo curso? & 71,8 & 28,2 \\
\hline 8. Os ensinamentos das disciplinas estão sendo proveitosos para o seu dia a dia? & 79 & 21 \\
\hline 9. Após a conclusão deste curso, você pretende fazer outro curso de graduação? & 60,5 & 39,5 \\
\hline 10. Pretende fazer um curso de pós-graduação (mestrado, especialização, MBA)? & 87,9 & 12,1 \\
\hline
\end{tabular}

Os discentes admitiram a relevância do curso para suas carreiras e indicaram que as disciplinas estavam sendo proveitosas para o seu dia a dia (79\%). Uma parte 
significativa $(71 \%)$ respondeu que, se fosse no momento do preenchimento do questionário, escolheria novamente o mesmo curso. Isso comprova que a maioria foi firme e decidida ao aprovar o curso e escolher a profissão.

Grande parte dos discentes respondeu ter participado de processos seletivos para outros cursos $(50,8 \%)$. Diante das tentativas sem sucesso, foi afirmada segurança no momento da segunda escolha $(76,6 \%)$, com uma observação mais madura para acertar a opção do curso.

Em relação à atuação profissional, uma parte considerável (75\%) já estava empregada ou já havia trabalhado quando ingressou no curso. Outra questão a destacar é o fato de que uma parte significativa mostrou interesse em dar seguimento aos estudos, por meio do ingresso em um curso de pós-graduação (87,9\%). Identicamente, são consideradas relevantes as respostas que apontaram o desejo de fazer outro curso de graduação após a conclusão do que estavam frequentando $(60,5 \%)$.

\section{Posicionamento sobre os fatores de influência}

A Figura 1 sistematiza as respostas dos discentes em relação aos fatores que os influenciaram na escolha do curso. Nas principais respostas obtidas, e em concordância com o modelo econômico da teoria vocacional, observa-se que a escolha profissional estava relacionada ao aumento dos ganhos. Outro fator relevante foi a busca por autonomia profissional, sendo que $47,58 \%$ dos entrevistados concordaram totalmente com isso, ou seja, quase metade, $23,39 \%$ concordaram parcialmente e apenas 3,23\% discordaram totalmente.

Junto a esse fator de escolha, a grande maioria $(83,06 \%)$ dos discentes respondeu que a profissão permitiria atuar em diferentes áreas/segmentos da empresa. Já $62,90 \%$ acreditavam que se tratava de um curso que se mantém atualizado com as evoluções do mercado. Essas respostas mostram que os respondentes possuíam certo conhecimento sobre o curso, uma vez que se trata de uma profissão regulamentada, o que remete a uma noção de segurança para o futuro.

O modelo sociológico defende que os filhos herdam os cargos dos pais, adotando um ofício com vínculo em cargos que se conciliem com a classe social de que fazem parte (Caplow, 1954). Na análise dos dados obtidos, vemos que essa teoria não condiz com a realidade da amostra em questão, em que 51,62\% dos entrevistados demonstrou que não tinha tradição familiar na carreira escolhida, enquanto apenas $16,13 \%$ concordaram totalmente com esse modelo. Ainda sobre tal modelo, pouco mais da metade dos entrevistados $(53,23 \%)$ afirmou que não pretendia conduzir a empresa da família, ao passo que apenas 17,74\% almejavam essa opção.

Outro dado relacionado ao modelo sociológico confirma que muitos $(71,78 \%)$ concordavam total e parcialmente que a formação na área ofereceria possibilidades para o exercício de uma profissão de prestígio e ascensão profissional mais rápida $(53,22 \%)$. 


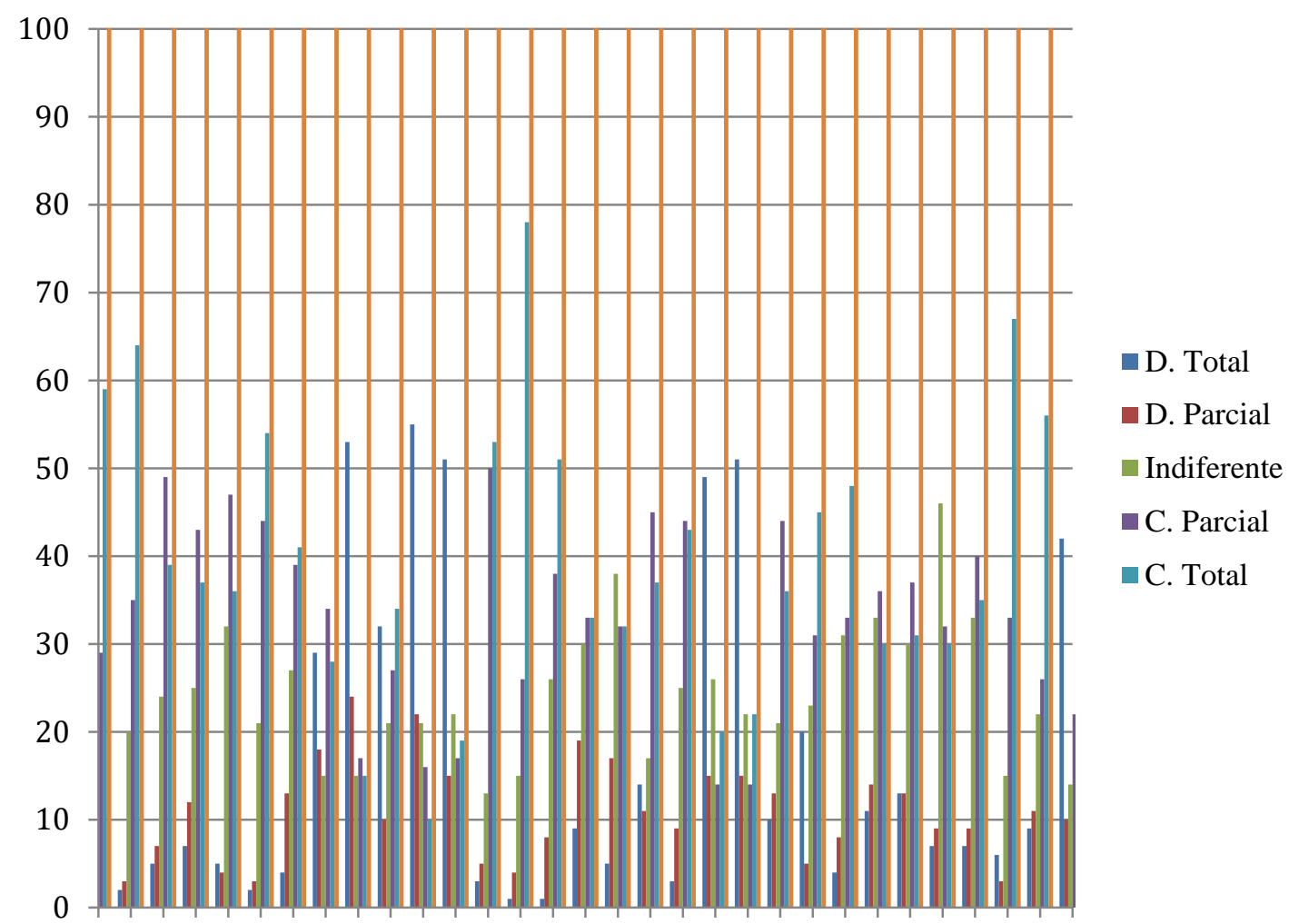

Figura 1. Motivos que influenciaram na escolha do curso Nota: Fonte: Dados da pesquisa

Outro fator de importância encontrado na análise diz respeito às condições oferecidas pela IES, pois $80,64 \%$ concordavam total e parcialmente que a instituição de ensino oferecia facilidades quanto à parte financeira e 66,13\% afirmaram ter o valor da mensalidade mais baixo. Ainda, 70,97\% dos entrevistados concordaram total e parcialmente que a instituição era de boa qualidade e passava uma imagem de credibilidade, experiência e tradição, além de também concordarem total e parcialmente $(63,13 \%)$ que estava situada em uma localização conveniente, em termos de acesso, segurança, etc.

Quando questionados sobre algum outro curso ter lhes interessado, destacou-se a heterogeneidade das respostas, pois 23,39\% discordaram totalmente, enquanto $22,52 \%$ concordaram totalmente. Ainda foi possível verificar que 41,13\% não receberam pressão da empresa onde trabalhavam durante ou antes da pesquisa e 33,87\% não estavam obtendo custeio por parte da empresa para fazer o curso.

Outro ponto relevante reside no fato de que 30,65\% acreditavam na indiferença de o contador exercer uma profissão sólida, que dá segurança e estabilidade de emprego, ao passo que $35,48 \%$ concordaram parcialmente que a profissão ofereceria maiores ofertas de emprego.

Em acordo com as teorias psicodinâmicas, 79,84\% tinham a percepção de que, ao escolher tal curso, ampliaram-se tanto sua cultura geral como seu desenvolvimento intelectual e $66,93 \%$ concordaram total e parcialmente que essa é a profissão que melhor contribuiria para o seu desenvolvimento pessoal. 


\section{Conclusão}

Por meio desta pesquisa pretendia-se experimentar referenciais teóricos que expusessem a percepção dos discentes quanto à motivação da escolha do curso de Ciências Contábeis e que conceitos se formam a partir disso. Para tanto, o estudo teve respaldo nos modelos econômico, psicológico e social, conforme indicações de Bomtempo (2005).

Com base nos dados coletados, conclui-se que o modelo econômico foi bem explorado e aceito no progresso da pesquisa. Conforme resultados sistematizados na Tabela 1, os motivos dominantes em relação à escolha do curso, com base nos precedentes econômicos, os estudantes indicaram que essa é uma profissão que ofereceria maiores ofertas de emprego, $(64,51 \%$ dos entrevistaram concordaram), que a profissão permitiria atuar em diferentes áreas/segmentos da empresa $(83,06 \%$ concordaram), que o mercado de trabalho não estava saturado para essa profissão $(54,84 \%$ concordaram) e que a profissão proporcionaria melhor remuneração $(53,22 \%)$.

As respostas mostram como essa profissão está introduzida na situação econômica, na sociedade e nos negócios, ficando claro como os estudantes se importavam em preparar-se para ficar à altura do mercado de trabalho, sempre disputado e árduo, conforme se observou na pesquisa realizada.

Em relação ao ponto de vista social, destacaram-se as seguintes questões: a carreira de um contador mostrava-se como uma profissão de prestígio $(71,78 \%$ concordaram) e que ofereceria ascensão profissional mais rápida $(53,23 \%$ concordaram). Essa análise encaixa-se no modelo sociológico, demonstrando a importância que a cultura e a sociedade têm no sistema de seleção, que se agrega a elementos como a classe social na qual o sujeito está posto. Entretanto, o mesmo modelo defende que os filhos herdam os cargos dos pais, adotando um ofício com vínculo em cargos que se conciliam com a classe social de que fazem parte (Caplow, 1954), porém 51,62\% discordaram e afirmaram não ter tradição familiar. Já 79,03\% concordaram ter recebido apoio da família, dos amigos, etc.

Por fim, vale evidenciar, dentro do modelo psicológico, uma razão citada pela maioria dos entrevistados: 79,84\% demonstraram que sua percepção ao escolher o curso era de que ampliaram tanto sua cultura geral como seu desenvolvimento intelectual e $66,93 \%$ concordaram total e parcialmente que a profissão selecionada era a que melhor contribuiria para seu desenvolvimento pessoal. Essa reação também atesta o que foi dito previamente em relação a alcançar os objetivos econômicos e sociais, levando-se em conta também a aflição de se preservar no mercado de trabalho em uma atividade que proporcione independência pessoal, financeira e intelectual.

Em relação às limitações da pesquisa e à organização de novos estudos, destacase a relevância de ampliar a análise das respostas ou complementar o instrumento utilizado com questões abertas, além da possibilidade de utilizar outro método por meio do qual seja possível coletar dados mais profundos sobre a motivação na escola da área para a formação superior. Espera-se, também, que os resultados do estudo possam ser proveitosos para os debates e as ações que envolvem os ingressantes. 


\section{Referências}

Almeida, R., Zwierewicz, M. e Pantoja, A. (2018). Perfil sociodemográfico, emocional e motivacional de estudantes da modalidade blended learning da Universidade Europeia do Atlântico - UNEATLÂNTICO. Imagens da Educação, 8(3), 1-17. Retrieved from http://periodicos.uem.br/ojs/index.php/ImagensEduc/article/view/44030/pdf.

Balbinotti, M. A. A. (2003). A noção transcultural de maturidade vocacional na teoria de Donald Super. Psicologia: reflexão e crítica, 16(3), 461-473. doi: 10.1590/S0102-79722003000300005

Bimrose, J. (2004). Psychodynamic theories. Retrieved from http://www.guidanceesearch.org/EG/impprac/ImpP2/traditional/psychodynamic/.

Bock, A. M. (2001). Psicologia sócio-histórica: uma perspectiva crítica em Psicologia. Psicologia sócio-histórica: uma perspectiva crítica em psicologia, 3 , 163-178.

Bomtempo, M. S. (2005). Análise dos fatores de influência na escolha pelo curso de graduação em administração: um estudo sobre as relações de causalidade através da modelagem de equações estruturais. (Dissertação de Mestrado em Administração de Empresas - Fundação Escola de Comércio Álvares Penteado FECAP).

Bomtempo, M. S., Silva, D., Garcia, M. N. e Coda, R. (2007). Estudo dos Motivos da Escolha do Curso de Administração de Empresa por meio da Modelagem de Equação Estrutural. XXXI Encontro Nacional dos Programas de Pós-Graduação em Administração - EnANPAD, Rio de Janeiro.

Caplow, T. (1954). The sociology of work. Minneapolis: University of Minnesota press.

Guimarães, S. É. R., Bzuneck, J. A. e Sanches, S. F. (2002). Psicologia educacional nos cursos de licenciatura: a motivação dos estudantes. Psicologia Escolar e Educacional, 6(1), 11-19. doi: 10.1590/S1413-85572002000100002.

Durso, S., Cunha, J., Neves, P. e Teixeira, J. (2016). Fatores motivacionais para o mestrado acadêmico: uma comparação entre alunos de ciências contábeis e ciências econômicas à luz da teoria da autodeterminação. Revista Contabilidade \& Finanças, 27(71). doi: 10.1590/1808-057x201602080

Kroenke, A., Cardoso, R. S. e Domingues, M. D. S. (2009). Fatores de atratividade para os estudantes de graduação em Ciências Contábeis na escolha da instituição de ensino. Anais do Seminários em Administração da FEA-USP, São Paulo, SP, Brasil, 12 .

Lens, W., Matos, L. e Vansteenkiste, M. (2008). Professores como fontes de motivação dos alunos: o quê e o porquê da aprendizagem do aluno. Educação, 31(1). Retrieved from http://revistaseletronicas.pucrs.br/ojs/index.php/faced/article/view/2752

Miranda, N. A. D. (2001). A escolha do curso e as expectativas profissionais em relação ao mercado de trabalho, dos alunos do ensino superior noturno de administração de empresas em instituições particulares. (Dissertação Mestrado - Centro Universitário Álvares Penteado - UNIFECAP, São Paulo). 
Pinheiro, R. G. e Santos, M. R. (2010). Fatores de escolha pelo curso de Ciências Contábeis - uma pesquisa com os graduandos na Capital e Grande São Paulo. In: SEMEAD, São Paulo. Anais. São Paulo: SEMEAD 2010. CD-ROM.

Saunders, M., Thornhill, A. e Lewis, P. (2012). Research Methods for Business Students. $6^{\mathrm{a}}$. ed. New York: Prentice-Hall.

Savickas, M. L. (1997). Career adaptability: an integrative construct for life-span, lifespace theory. The career development quarterly, 45(3), 247-259. doi: 10.1002/j.2161-0045.1997.tb00469.x

Schein, E. H. (1994). Organizational Psychology, Prentice-Hall.

Sparta, M. (2003). A exploração e a indecisão vocacionais em adolescentes no contexto educacional brasileiro (Dissertação de mestrado, Universidade Federal do Rio Grande do Sul).

Super, D. E. e Bohn Junior, M. J. (1976). Psicologia Ocupacional. São Paulo: Atlas.

Super, D. E. (1957). The psychology of careers. New York: Harper \& Row.

Watkins, C. E. e Savickas, M. L. (1990). Psychodynamic career counseling. Career counseling: Contemporary topics in vocational psychology (pp. 79-116). Hillsdale, NJ: Erlbaum.

Data de recepção: $06 / 04 / 2017$

Data da revisão: $22 / 10 / 2018$

Data do aceite: $13 / 01 / 2019$

\footnotetext{
' Publicado originalmente em 1942.
} 